\title{
Analisis Perubahan Penggunaan Lahan di Kabupaten Bandung Barat
}

\author{
Analysis of Land Use Change in West Bandung District \\ Yohanes Christian $^{1 \star}$, Chay Asdak², Dwi Rustam Kendarto² \\ ${ }^{1}$ Mahasiswa Magister Teknologi Agroindustri, Fakultas Teknologi Industri Pertanian, Universitas Padjadjaran \\ ${ }^{2}$ Departemen Teknik Pertanian dan Biosistem, Fakultas Teknologi Industri Pertanian, Universitas Padjadjaran \\ *Email: yohanes.christian092@gmail.com
}

Diterima: 10 Februari 2021; Disetujui: 30 Juni 2021

\begin{abstract}
ABSTRAK
Kebutuhan hidup pada Kabupaten Bandung Barat akan bertambah seiring dengan tingginya pertumbuhan jumlah penduduk. Oleh karena itu, pembangunan akan bertambah seiringnya meningkatnya jumlah penduduk, sehingga perlu adanya pertimbangan keseimbangan lingkungan agar memenuhi kebutuhan yang diperlukan oleh masyarakat. Perubahan tataguna lahan menjadi konsekuensi dengan adanya pembangunan. Tujuan dari penelitian ini adalah mengetahui pola perubahan penggunaan lahan dan menganalisis penggunaan lahan wilayah Kabupaten Bandung Barat. Metode penelitian yang digunakan adalah metode analisis deskriptif, dengan menggunakan fakta-fakta yang ada dengan menggunakan data hidroklimatologi, tataguna lahan, dan jenis tanah. Software ArcGis 10.3 digunakan untuk mengolah data spasial, melakukan analisis spasial, mencakup pembuatan peta, penentuan luas daerah, overlay peta dan penyajian peta. Selama dalam kurun waktu 7 tahun terdapat banyak perubahan tataguna lahan yang ada pada wilayah Kabupaten Bandung Barat berbentuk hutan, perkebunan, pertanian lahan kering dan basah, serta lahan terbangun. Terdapat beberapa pola perubahan penggunaan lahan yang terjadi. Terdapat 11.000 ha lebih perubahan yang ada pada wilayah Kabupaten Bandung Barat. Penggunaan yang berubah terdapat pada Tanaman Pertanian Lahan kering dan basah, Perkebunan, Hutan, dan lahan terbangun. Perkebunan mengalami perubahan yang cukup banyak, dikarenakan banyaknya profesi dari masyarakat Kabupaten Bandung Barat yang menjadi petani, dan mengsumberkan mata pencarian dari hasil kebun.
\end{abstract}

Kata kunci: Kabupaten Bandung Barat; tataguna lahan; perubahan lahan

\begin{abstract}
The necessities of life in West Bandung Regency will increase along with the high population growth. Therefore, development will increase along with the increase in population, so it is necessary to consider environmental balance in order to meet needed by the community. Changes in land use are a consequence of development. The purpose of this study was to determine the pattern of land use change and to analyze land use in West Bandung Regency. The research method used is descriptive analysis method, using existing facts using hydro-climatological data, land use, and soil types. ArcGis 10.3 software is used to process spatial data, perform spatial analysis, including map making, determining area size, map overlay and map presentation. During a period of 7 years there have been many changes in land use in the West Bandung Regency in the form of forests, plantations, dry and wet land agriculture, and built-up land. There are several patterns of land use change that have occurred. There are more than 11,000 ha of changes in the West Bandung Regency area. The uses that have changed are in agricultural crops dry and wet land, plantations, forests, and developed land. Plantation has undergone quite a lot of changes, due to the many professions of the people of West Bandung Regency who become farmers, and source their livelihoods from garden products.
\end{abstract}

Keywords: landuse; landuse change; West Bandung Regency.

\section{PENDAHULUAN}

Perubahan lahan dengan menggunakan data spasial sangat diperlukan untuk mengetahui lokasi-lokasi yang terdapat terjadinya perubahan lahan. Perubahan penggunaan lahan merupakan fenomena global yang menjadi perhatian peneliti di berbagai negara di dunia. Kajian perubahan penggunaan lahan berkembang sangat cepat dan menghasilkan banyak pendekatan (Sitorus, 2012). Lahan adalah ruang fungsional yang diperuntukkan untuk mewadahi berbagai penggunaan. Dalam perspektif ini lahan mengakomodasi pertumbuhan kawasan yang didorong oleh pertumbuhan penduduk dan ekspansi ekonomi.

Meningkatnya jumlah penduduk dan ekspansi ekonomi meningkatkan kompleksitas fungsi kawasan (Parlindungan,
2007). Hasil dari penelitian Nuraeni (2014) menganalisis perubahan dalam kurun waktu 2002-2014 pada wilayah kabupaten Bandung barat. Dalam kurun waktu tersebut terjadi perubahan lahan di kawasan kabupaten Bandung. Perubahan tersebut terdapat lima pola, yaitu dimulai dari Lahan basah menjadi lahan bangunan, lahan kering dijadikan lahan bangunan, lahan basah dijadikan lahan kering, perkebunan dijadikan lahan bangunan dan hutan dijadikan juga menjadi lahan bangunan sedangkan untuk badan air tidak mengalami perubahan. Hasil analisis dari (Nuraeni, 2014) juga menghasilkan Kondisi eksisting penggunaan lahan di Kabupaten Bandung tahun 2012 menunjukkan inkonsistensi dengan alokasi ruang dalam rencana tata ruang sebesar 43.896,05 ha. Proporsi penyimpangan terbesar dari alokasi pada RTRW terjadi pada jenis peruntukan TPLB dan hutan menjadi TPLK 
diikuti dengan jenis peruntukan hutan menjadi perkebunan serta jenis peruntukan TPLB menjadi lahan terbangun.

Kabupaten Bandung Barat, Jawa Barat merupakan hasil pemekaran daerah Kabupaten Bandung Kabupaten Bandung Barat didominasi oleh kemiringan lereng yang sangat terjal $>40(46,5 \%)$. Hal ini tersebut menunjukkan bahwa Kabupaten Bandung Barat wilayahnya didominasi oleh kawasan yang berfungsi lindung, sedangkan kawasan yang wilayahnya bertopografi datar dan bergelombang sampai berbukit relatif kecil (Sa'at, 2012). Sumber daya merupakan kunci bagi kelangsungan hidup manusia. Keterbatasan lahan dapat menimbulkan berbagai konflik antar kepentingan dalam masyarakat. Baik untuk kebutuhan rumah tangga, industri, pertanian atau lainnya. Fasilitas-fasilitas harus dikelola dengan bijak yang melibatkan berbagai kelompok kepentingan.

Kabupaten Bandung Barat memiliki \pm 90 sungai, dengan sungai utama adalah Sungai Citarum. Pada awal berdiri sebagai daerah otonom pada tahun 2007 Kabupaten Bandung Barat mewarisi sekitar 1,4 juta jiwa dari total penduduk Kabupaten Bandung. Saat ini berdasarkan data statistik jumlah tersebut terus bertambah menjadi 1.648.387 jiwa (BPS, 2016). Pada 2019 sudah bertambah menjadi 1.691.691 jiwa dengan jumlah penduduk laki-laki 860.394 jiwa dan perempuan 831.297 jiwa dengan rasio jenis kelamin. Menurut BPS Bandung Barat tahun 2016, yang tertuang pada Kabupaten Bandung Barat Dalam Angka setiap tahunnya jumlah kelahiran yang ada sebesar 2800 jiwa/tahun. Data tersebut dapat diperkirakan dengan peningkatan jumlah penduduk setiap harinya di Kabupaten Bandung Barat akan mempengaruhi naiknya tingkat kebutuhan hidup untuk makhluk hidup yang ada pada Kabupaten Bandung Barat.

Berbagai fenomena perubahan penggunaan lahan telah terjadi dari waktu ke waktu. Perubahan penggunaan lahan yang terjadi sejalan dengan semakin meningkatnya pertambahan jumlah penduduk yang secara langsung berdampak pada kebutuhan terhadap lahan yang semakin meningkat (Kusrini, 2011). Dinamika perubahan penggunaan lahan seringkali menyebabkan perubahan kualitas lahan termasuk sumber daya air dikarenakan ketidaksesuaian Antara kemampuan lahan dan penggunaannya. Pengamatan terhadap land-use change melibatkan pengamatan dan pengkajian langsung di lokasi (Wahyuni, 2014).

Analisis tata guna lahan merupakan analisis dari perwujudan fisik dari objek-objek yang menutupi lahan yang sangat berkaitan dengan kegiatan pada lahan yang ada di Kabupaten Bandung Barat. Tata guna lahan penting untuk melihat kesesuaian lahan dalam perencanaan penggunaan lahan, karena lahan sangat penting untuk memenuhi kebutuhan hidup manusia. Manusia adalah pengendali utama di bumi ini. Di mana aktivitas manusia sangat berkaitan dengan penggunaan lahan maka dari itu perlu adanya dasar-dasar perencanaan tataguna lahan agar manusia dapat memanfaatkan lahan sesuai dengan potensi yang dimiliki lahan tersebut dengan baik (Maulana, 2018). Tataguna lahan memiliki sinergi dengan karakteristik dan proses lingkungan, produktivitas lahan, iklim dan siklus hidrologi. Proses dari pembuatan peta tata guna lahan Kabupaten Bandung Barat dilakukan untuk mengetahui kondisi lahan tata guna lahan. Potensi dari perubahan lahan mempunyai konsekuensi dari perubahan penutupan lahan untuk iklim, unsur-unsur yang ada pada tanah dan kompleksitas sulit tanpa mengetahui adanya informasi penggunaan lahan. Hasil dari analisis ini dapat mengetahui fasilitas apa saja yang menutupi lahan di Kabupaten Bandung Barat. Peta tata guna lahan dijadikan pertimbangan untuk menentukan lokasi konservasi yang tepat untuk dijadikan rekomendasi. Hasil analisis tata guna lahan dilakukan berdasarkan hasil yang diperoleh dari Kantor dinas yang terkait. Sebaran dan luasan yang ada pada Kabupaten Bandung Barat diketahui dan dijadikan lahan yang lebih produktif jika lahan sebelumnya belum dimaksimalkan.

\section{METODOLOGI}

Penelitian dilakukan di kabupaten Bandung Barat yang terdiri dari 16 kecamatan. Penelitian dilakukan pada bulan November 2020. Pengolahan data dilakukan di Kampus FTIP, Universitas Padjadjaran, Jatinangor. Alat yang digunakan pada penelitian ini meliputi Global Positioning System(GPS) digunakan untuk referensi pengukuran koordinat. Peralatan tulis, perangkat netbook dengan RAM 2GB. Software Spreadseet untuk menyimpan dan mengolah data tabular. Software ArcGis 10.3 digunakan untuk mengolah data spasial, melakukan analisis spasial, mencakup pembuatan peta, penentuan luas daerah, overlay peta dan penyajian peta. Kamera digital yang digunakan untuk pengambilan dokumentasi pada saat penelitian.

Bahan-bahan yang digunakan untuk penelitian ini diperoleh dari Kantor Bupati Bandung Barat, dan BAPPEDA provinsi Jawa Barat. Data yang diperlukan untuk penelitian ini adalah Data Penduduk Kabupaten Bandung Barat, Data Tata Guna Lahan Kabupaten Bandung Barat, Peta Kabupaten Bandung Barat, dengan skala 1:25.000.

Metode Penelitian yang digunakan adalah metode analisis deskriptif, yang bertujuan untuk mengetahui keadaan yang sesungguhnya dengan menggunakan faktafakta yang ada dengan menggunakan data yang tersedia di lapangan ataupun di dinas-dinas yang terkait dengan penelitian ini. Teknik pengumpulan data yang dipakai adalah observasi lapangan, studi literatur dan studi dokumentasi.

Pengumpulan data yang terdiri dari beberapa tahapan menjadi awal dari penelitian ini. Pada pengumpulan data tahap pendahuluan akan dimulai dari pengumpulan kajian pustaka dari literasi yang ada. Data awal yang sudah terkumpul akan digabungkan dengan data selanjutnya yaitu pengambilan data sekunder yang diambil dari kantor dinas yang terkait pada penelitian ini. Kantor dinas yang terkait pada penelitian ini adalah kantor administrasi Kabupaten Bandung Barat, dan BAPPEDA (Badan Perencanaan dan Pembangunan Daerah) Provinsi Jawa barat.

Pengumpulan data yang sudah ada digabungkan lalu digunakan untuk dilakukan perhitungan agar dapat dilakukan analisis. Analisis tata guna lahan merupakan analisis dari perwujudan fisik dari objek-objek yang menutupi lahan yang sangat berkaitan dengan kegiatan pada lahan yang ada di Kabupaten Bandung Barat. Tataguna lahan memiliki sinergi dengan karakteristik dan proses lingkungan, produktivitas lahan, iklim dan siklus hidrologi. Proses dari pembuatan peta tata guna lahan Kabupaten Bandung Barat dilakukan untuk mengetahui kondisi lahan tata guna lahan. Potensi dari perubahan lahan mempunyai konsekuensi dari perubahan penutupan lahan untuk iklim, unsur-unsur yang ada pada tanah dan kompleksitas sulit tanpa mengetahui adanya informasi penggunaan lahan. Hasil dari analisis ini dapat mengetahui fasilitas apa saja yang menutupi lahan di Kabupaten Bandung Barat. Peta tata guna lahan dijadikan pertimbangan untuk menentukan lokasi konservasi yang tepat untuk dijadikan rekomendasi. Sebaran dan luasan yang ada pada Kabupaten Bandung Barat diketahui dan dijadikan lahan yang lebih produktif jika lahan sebelumnya belum dimaksimalkan. 


\section{HASIL DAN PEMBAHASAN}

Data-data dasar yang berbentuk spasial, digital dan sekunder yang didapat dan digunakan dalam penelitian ini diperoleh dari instansi atau dinas pemerintah yang ada di provinsi Jawa Barat Dinas tersebut adalah BAPPEDA Jawa Barat, Dinas PSDA dan Pusat Data dan Analisa Pembangunan Jawa Barat. Kabupaten Bandung Barat meliputi 16 kecamatan yaitu Kecamatan Rongga, Gununghalu, Sindangkerta, Cililin, Cihampelas, Cipongkor, Batujajar, Saguling, Cipata, Padalarang, Ngamprah, Parongpong, Lembang, Cisarua, Cikalong Wetan, dan Cipeundeuy.

Tata guna lahan daerah tangkapan yang ada di kabupaten Bandung Barat terdiri dari belukar, hutan tanaman, dan perkebunan milik masyarakat. Dalam analisis perubahan penggunaan lahan diperlukan perencanaan penggunaan lahan yang berfungsi sebagai rancangan bagaimana manusia dapat memanfaatkan secara efisien dan menguntungkan guna memenuhi berbagai macam kebutuhan. Dari pernyataan tersebut merupakan suatu contoh perubahan penggunaan lahan yang semakin lama semakin langka dari tahun ke tahun jika tanpa terpelihara keberadaannya manusia sendiri yang akan rugi terutama untuk generasi yang akan datang perlu untuk dipikirkan (Raharja, 2012). Tataguna lahan yang ada pada kabupaten Bandung Barat peruntukannya tersebar secara merata pada setiap kecamatannya.

Tabel 1. Luas area Kecamatan Di Kabupaten Bandung Barat

\begin{tabular}{rlr}
\hline No & \multicolumn{1}{c}{ Kecamatan } & Luas Area $\left(\mathrm{km}^{2}\right)$ \\
\hline 1 & Rongga & 113,12 \\
2 & Gununghalu & 160,64 \\
3 & Sindangkerta & 120,47 \\
4 & Cililin & 77,79 \\
5 & Cihampelas & 46,99 \\
6 & Cipongkor & 79,96 \\
7 & Batujajar & 32,04 \\
8 & Saguling & 51,46 \\
9 & Cipatat & 126,05 \\
10 & Padalarang & 51,4 \\
11 & Ngamprah & 36,01 \\
12 & Parongpong & 45,15 \\
13 & Lembang & 95,56 \\
14 & Cisarua & 55,11 \\
15 & Cikalong Wetan & 112,93 \\
16 & Cipeundeuy & 101,09 \\
\hline & Total & $1.305,77$ \\
\hline
\end{tabular}

Sumber: Hasil Analisa, 2019.

Penggunaan lahan perlu diketahui untuk menentukan besarnya luasan wilayah yang digunakan yang untuk mengetahui saran-sarana apa saja yang ada di Kabupaten Bandung Barat.

Perubahan tataguna lahan yang ada pada Kabupaten Bandung Barat dilihat dengan menggunakan data tata guna lahan Kabupaten Bandung Barat tahun 2012. Menurut Nuraeni pada tahun 2012, pada penelitiannya tentang perubahan lahan pada Kabupaten Bandung Barat (Gambar 2).

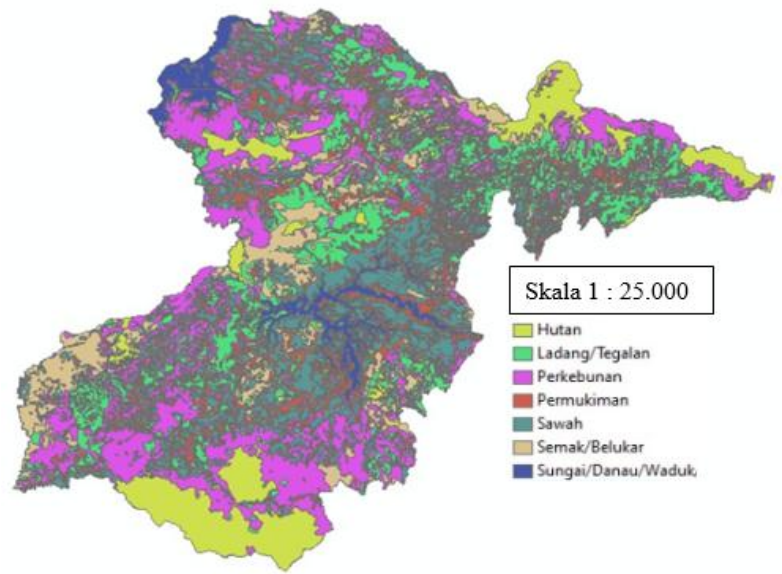

Gambar 1. Tata guna Lahan Kabupaten Bandung Barat

Tabel 2. Tata Guna Lahan Kabupaten Bandung Barat Tahun 2019

\begin{tabular}{lr}
\hline \multicolumn{1}{c}{ Tata Guna Lahan } & Area (ha) \\
\hline Perkebunan & $16.413,80$ \\
Tegalan/Ladang & $18.525,45$ \\
Sawah & $23.719,14$ \\
Kebun Campuran & $12.599,99$ \\
Semak Belukar & $8.273,26$ \\
Gedung atau Bangunan & $22.157,00$ \\
Hutan Primer & $13.112,21$ \\
Hutan Sekunder & $12.474,83$ \\
Kawasan Zona Industri & 1,00 \\
Danau/Waduk/Sungai & $3.301,00$ \\
Perkebunan & $16.413,80$ \\
\hline \multicolumn{2}{c}{ Total } \\
\hline
\end{tabular}

Sumber: Hasil Perhitungan, 2019

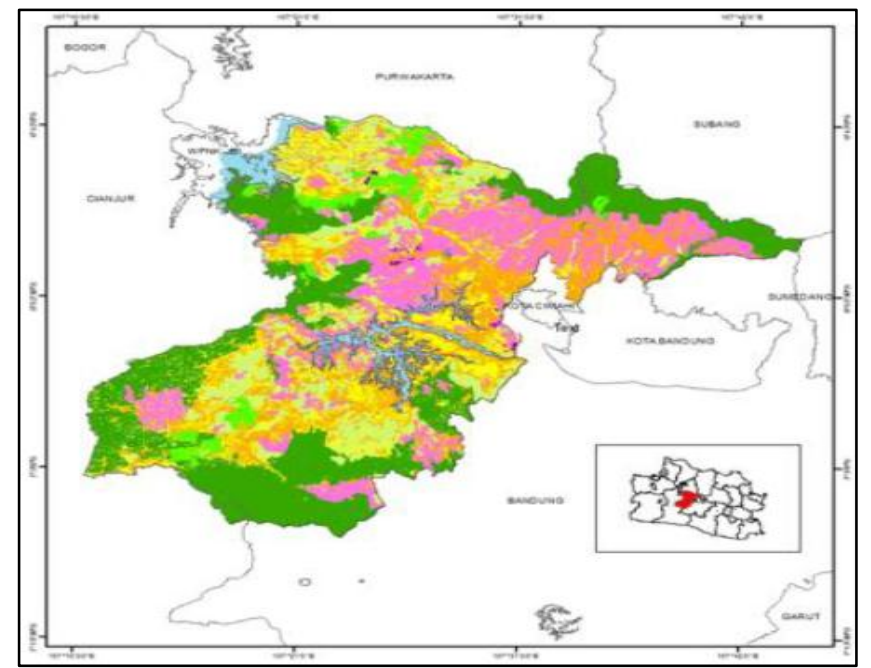

Gambar 2. Tata guna Lahan Kabupaten Bandung Barat Tahun 2012

Penggunaan lahan di Kabupaten Bandung mengalami perubahan dengan lima pola perubahan utama mulai dari yang terluas yaitu TPLB menjadi lahan terbangun, TPLK menjadi lahan terbangun, TPLB menjadi TPLK. Perkebunan menjadi lahan terbangun dan hutan menjadi lahan terbangun. Penggunaan lahan badan air tidak mengalami perubahan dan Faktor utama yang mempengaruhi perubahan penggunaan lahan pertanian menjadi lahan terbangun yaitu pertumbuhan penduduk. 
Penggunaan lahan pada tahun 2012 disajikan pada Tabel 3.

Tabel 3. Penggunaan Lahan Di Kabupaten Bandung Barat Tahun 2012

\begin{tabular}{|c|c|}
\hline Jenis Penggunaan Iahan & Luas (ha) \\
\hline Hutan & $37.411,00$ \\
\hline Perkebunan & $5.565,00$ \\
\hline TPLK & $43.342,00$ \\
\hline TPLB & $18.829,05$ \\
\hline Lahan Terbangun & $22.129,63$ \\
\hline Badan Air & $3.301,00$ \\
\hline
\end{tabular}

Sumber: Nuraeni, 2014

Analisis perubahan dilakukan dengan melakukan dengan melakukan penyamaan penggunaan lahan yang ada pada tahun 2012 dengan kondisi pada tahun 2019. Pola perubahan lahan dapat dilihat pada Tabel 4. Pola perubahan penggunaan lahan terbesar adalah pada penggunaan tanaman pertanian lahan kering atau biasa disebut TPLK yang dijadikan perkebunan. Pemanfaatan ruang yang ada pada Kabupaten Bandung Barat terjadi pada TPLK, Hutan, dan lahan terbangun jenis peruntukan menjadi perkebunan dan tanaman pertanian lahan basa atau TPLB.

Berdasarkan data yang ada diperoleh perubahan lahan cenderung mengalami adanya penambahan luas untuk perkebunan sebanyak $10.848,80$ ha. Penambahan lahan pada perkebunan didominasi karena banyaknya masyarakat yang menjadi profesi petani buah-buahan dan membeli lahan kosong untuk dijadikan kebun. Hal itu dilakukan untuk menaikan kondisi ekonomi masyarakat Kabupaten Bandung Barat. Perubahan struktur ekonomi menyebabkan kegiatan pertanian pertanian semakin meningkat agar kebutuhan hidup masyarakat dan penggunaan lahan terbangun yang hanya bertambah dengan luas 2.441,63 ha.

Tabel 4. Luas Penggunaan Lahan 2012, 2019, dan Perubahannya

\begin{tabular}{lrrr}
\hline \multirow{2}{*}{$\begin{array}{c}\text { Jenis } \\
\text { Penggunaan }\end{array}$ lahan (ha) } & \multicolumn{2}{c}{ Tahun } & Perubahan \\
\cline { 2 - 3 } & \multicolumn{1}{c}{2012} & \multicolumn{1}{c}{2019} & \\
\hline Hutan & $37.411,00$ & $25.587,04$ & $-11.823,96$ \\
Perkebunan & $5.565,00$ & $16.413,80$ & $10.848,80$ \\
TPLK & $43.342,00$ & $39.398,70$ & $-3.943,30$ \\
TPLB & $18.829,05$ & $23.719,14$ & $4.890,09$ \\
Lahan & $22.129,63$ & $22.158,00$ & 28,37 \\
Terbangun & $3.301,00$ & $3.301,00$ & 0,00 \\
Badan Air & & & \\
\hline
\end{tabular}

Terjadinya perubahan lahan yang ada pada wilayah Kabupaten Bandung Barat karena kebutuhan akan ruang atau lahan yang semakin meningkat tetapi ketersedian lahan yang ada terbatas. Selama dalam kurun waktu 7 tahun terdapat banyak perubahan tataguna lahan yang ada pada wilayah Kabupaten Bandung Barat berbentuk hutan, perkebunan, pertanian lahan kering dan basah, serta lahan terbangun. Sawah dan perkebunan mengalami peningkatan dan menjadi hal yang paling menarik, karena dari sini dapat dilihat komitmen dari pemerintah daerah maupun masyarakat Kabupaten Bandung Barat akan pentingnya ketersediaan air yang dihasilkan oleh perkebunan tapi juga mengganti hutan. Perkebunan yang mengalami perubahan juga disebabkan banyak masyarakat yang menyukai kopi, karena sebagian besar perkebunan yang ada di Wilayah
Kabupaten Bandung Barat yaitu kebun kopi dengan luas $3.015,40$ ha diikuti dengan kebun teh, yaitu 1.893,68 ha, lalu kebun kelapa seluas 1.339,00 dan kebun cocoa yang hanya ada di kecamatan Cililin seluas 14,44 ha. Pertanian lahan kering dan hutan mengalami perubahan paling besar yang dijadikan persawahan dan perkebunan awalnya karena pertanian lahan kering sudah tidak dipakai dan banyak yang menjadi belukar sehingga diubah menjadi sawah ataupun kebun, hal tersebut didapat berdasarkan informan, yaitu masyarakat yang ada tinggal di kecamatan Pasirhalang.

Pemilik lahan atau perkebunan banyak yang menanam buah-buahan, seperti mangga, durian, jeruk, pisang, pepaya, dan salak karena lebih menguntungkan dari hasil penjualan. Perubahan yang dilakukan untuk membuat perkebunan menunjukan bahwa kebutuhan lahan yang ada di wilayah Kabupaten Bandung Barat untuk melakukan kegiatan budidaya pertanian meningkat dari tahun 2012.

Kondisi wilayah yang seperti Kabupaten Bandung Barat mempunyai penggunaan lahan cukup baik untuk masyarakat gunakan sebagai fasilitas-fasilitas untuk memenuhi kegiatan. Penggunaan lahan yang ada pada kabupaten Bandung Barat diketahui agar dapat menentukan letak-letak perubahan penggunaan lahan. Berikut dapat dilihat perubahan yang terjadi dari tahun 2012 sampai dengan 2019:

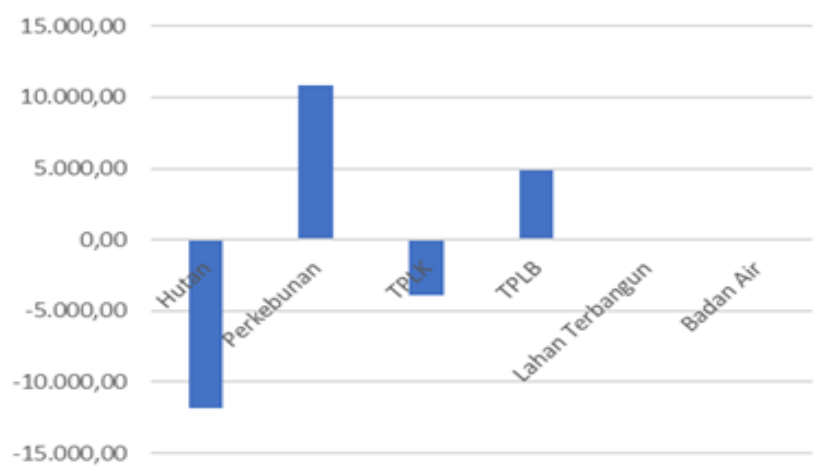

Gambar 4. Laju Perubahan Penggunaan Lahan tahun 2012 hingga 2019

Gambar 4 memberitahukan laju dari perubahan penggunaan lahan pada periode 2012 dan 2019. Perubahan penggunaan lahan telah terjadi di kabupaten Bandung Barat, hal tersebut diduga karena adanya pertambahan jumlah penduduk sehingga membutuhkan lahan untuk dijadikan lahan pekerjaan ataupun dijadikan untuk tanaman-tanaman yang dapat menambah ketersediaan air serta agar banyaknya kegiatan ekonomi pada sektor pertanian. Perkembangan dan pembangunan daerah yang dilakukan pemerintah dalam menyediakan infrastruktur dan pelayanan dapat berimplikasi terhadap peningkatan kebutuhan lahan. Semakin pesatnya pembangunan yang dilakukan menimbulkan keterbatasan dan kebutuhan lahan yang meningkat didukung oleh bertambahnya jumlah penduduk, kegiatan sosial, kegiatan ekonomi berdampak semakin meningkatnya perubahan penggunaan lahan di wilayah tersebut. Pertumbuhan populasi dan perkembangan peradaban manusia, penguasaan dan penggunaan lahan mulai terusik (Adipka dkk., 2018). Hal tersebut terjadi juga pada Wilayah Kabupaten Bandung Barat. 
Tabel 5. Jumlah Pertambahan Penduduk Dari Tahun 2010 sampai 2019 di Kabupaten Bandung Barat

\begin{tabular}{ccc}
\hline No & Tahun & Jumlah \\
\hline 1 & 2010 & 1.522 .076 \\
2 & 2011 & 1.545 .118 \\
3 & 2012 & 1.567 .398 \\
4 & 2013 & 1.588 .781 \\
5 & 2014 & 1.609 .512 \\
6 & 2015 & 1.629 .423 \\
7 & 2016 & 1.648 .387 \\
8 & 2017 & 1.666 .510 \\
9 & 2018 & 1.683 .711 \\
10 & 2019 & 1.691 .691 \\
\hline
\end{tabular}

Perubahan lahan yang ada terjadi karena adanya peningkatan jumlah penduduk setiap tahunnya, kondisi ekonomi masyarakat dan kondisional. Jumlah penduduk di Kabupaten Bandung Barat disajikan pada Tabel 5.

Hal ini menyatakan bahwa adanya perubahan lahan yang terjadi pada Kabupaten Bandung Barat diartikan bahwa tataguna lahan hanya bersifat sementara dan merupakan disebabkan oleh adanya pertumbuhan dan perubahan struktur sosial ekonomi yang berkembang baik untuk tujuan menaikan ekonomi masyarakat (2011, Kusrini). Faktor yang mempengaruhi perubahan penggunaan lahan dan tutupan lahan yaitu faktor dari fisik lahan dan faktor ekonomi yang dipengaruhi kondisi sosial dan budaya masyarakat setempat sehingga pola penggunaan lahan suatu daerah yang diakibatkan oleh pertambahan penduduk pada Kabupaten Bandung Barat.

\section{KESIMPULAN}

Kesimpulan dari penelitian ini adalah pemanfaatan ruang yang ada pada Kabupaten Bandung Barat terjadi pada TPLK, Hutan, dan lahan terbangun jenis peruntukan menjadi perkebunan dan TPLB.

Pola perubahan penggunaan lahan yang terjadi pada kabupaten Bandung Barat diperoleh perubahan lahan cenderung mengalami adanya penambahan luas untuk perkebunan sebanyak $10.848,80$ ha. Penambahan lahan pada perkebunan didominasi karena banyaknya masyarakat yang menjadi profesi petani buah-buahan dan membeli lahan kosong untuk dijadikan perkebunan.

Perkebunan yang mengalami perubahan, sebagian besar perkebunan yang ada di Wilayah Kabupaten Bandung Barat yaitu kebun kopi dengan luas 3.015,40 ha diikuti dengan kebun teh, yaitu $1.893,68$ ha, lalu kebun kelapa seluas $1.339,00$ dan kebun cocoa yang hanya ada di kecamatan Cililin seluas 14,44 ha.

\section{DAFTAR PUSTAKA}

Adipka, A., I Gede Sugiyanta, Irma Lusi Nugraheni. (2018). Analisis Perubahan Penggunaan Lahan Persawahan Di Kota Metro Antara Tahun 2000-2015. Jurnal Penelitian Geografi.

Badan Pusat Statistik Kabupaten Bandung Barat. (2016). Kabupaten Bandung Barat Dalam Angka (1102001.32). Cv Nugraha.

Direktorat Jenderal Cipta Karya PUPR. (1996). Modul Proyeksi Kebutuhan Air Dan Identifikasi Pola. In Perencanaan Jaringan Pipa Transmisi Dan Distribusi Air Minum. Kementerian Pekerjaan Umum dan Perumahan Rakyat.

Kusrini. (2011). Perubahan Penggunaan Lahan dan Faktor yang Mempengaruhinya Di Kecamatan Gunungpati
Kota Semarang. Geografi Indonesia, 25(1), 25-42.

Maulana, I. (2018). Analisis Faktor Perubahan Penggunaan Lahan Di Kabupaten Bekasi Pada Tahun 2015 Dengan Aplikasi Sistem Informasi Geografis Dan Penginderaan Jauh. Skripsi. Fakultas Tarbiyah dan Keguruan. UIN Syarif Hidayatullah Jakarta.

Nuraeni, R. (2014). Analisis Perubahan Penggunaan Lahan dan Arahan Penggunaan Lahan Wilayah di Kabupaten Bandung.

Parlindungan, J. (2007). Tata Guna Lahan Dan Pertumbuhan Kawasan. Universitas Brawijaya.

Raharja, R. T. (2012). Analisis Perubahan Penggunaan Lahan Dengan Menggunakan Aplikasi PJ Dan SIG di Pesisir Kecamatan Sluke Kabupaten Rembang Tahun 2004-2012. Skripsi. Universitas Muhamadiah Surakarta.

Sa'at, J. (2012). Tesis: Kajian Daya Dukung Sumber Air Hujan terhadap Rencana Tata Ruang Wilayah (RTRW) Kota Depok tahun 2010 (Magister Sumber Daya Air (ed.)). Universitas Indonesia.

Sitorus, S. R. P. (2012). Analisis Pola Perubahan Penggunaan Lahan Dan Perkembangan Wilayah Di Kota Bekasi, Provinsi Jawa Barat. Jurnal Tanah Lingkungan, 14(1410-7333), 21-28.

Wahyuni, S. (2014). Analisis Perubahan Penggunaan Lahan dan Penutupan Lahan Tahun 2003 dan 2013 di Kabupaten Dairi. Jurnal Online Agroeteknologi, 2(2337), 1310-1315. 
TEKNOTAN, Vol. 15, No. 1, Agustus 2021

Halaman ini sengaja dikosongkan 